\title{
Carriage of antimicrobial-resistant bacteria in a high-density informal settlement in Kenya is associated with environmental risk-factors
}

Sylvia Omulo 1,2,5*0, Eric T. Lofgren', Svetlana Lockwood', Samuel M. Thumbi 1,2,3, Godfrey Bigogo ${ }^{3}$, Alice Ouma ${ }^{3}$, Jennifer R. Verani ${ }^{4}$, Bonventure Juma ${ }^{4}$, M. Kariuki Njenga ${ }^{1,2}$, Samuel Kariuki ${ }^{4}$, Terry F. McElwain ${ }^{1,6}$, Guy H. Palmer ${ }^{1,2,6}$ and Douglas R. Call ${ }^{1,2,6}$

\begin{abstract}
Background: The relationship between antibiotic use and antimicrobial resistance varies with cultural, socio-economic, and environmental factors. We examined these relationships in Kibera, an informal settlement in NairobiKenya, characterized by high population density, high burden of respiratory disease and diarrhea.

Methods: Two-hundred households were enrolled in a 5-month longitudinal study. One adult ( $\geq 18$ years) and one child ( $\leq 5$ years) participated per household. Biweekly interviews $(n=1516)$ that included questions on water, sanitation, hygiene, and antibiotic use in the previous two weeks were conducted, and 2341 stool, 2843 hand swabs and 1490 drinking water samples collected. Presumptive E. coli $(n=34,042)$ were isolated and tested for susceptibility to nine antibiotics.

Results: Eighty percent of presumptive E. coli were resistant to $\geq 3$ antibiotic classes. Stool isolates were resistant to trimethoprim (mean: 81\%), sulfamethoxazole (80\%), ampicillin (68\%), streptomycin (60\%) and tetracycline (55\%). Ninety-seven households reported using an antibiotic in at least one visit over the study period for a total of 144 episodes and 190 antibiotic doses. Enrolled children had five times the number of episodes reported by enrolled adults (96 vs. 19). Multivariable linear mixed-effects models indicated that children eating soil from the household yard and the presence of informal hand-washing stations were associated with increased numbers of antimicrobial-resistant bacteria (counts increasing by $0.27-0.80 \log _{10}$ and $0.22-0.51 \log _{10}$ respectively, depending on the antibiotic tested). Rainy conditions were associated with reduced carriage of antimicrobial-resistant bacteria (1.19 to $3.26 \log _{10}$ depending on the antibiotic tested).

Conclusions: Antibiotic use provided little explanatory power for the prevalence of antimicrobial resistance. Transmission of resistant bacteria in this setting through unsanitary living conditions likely overwhelms incremental changes in antibiotic use. Under such circumstances, sanitation, hygiene, and disease transmission are the limiting factors for reducing the prevalence of resistant bacteria.
\end{abstract}

Keywords: Sanitation, Antimicrobial resistance, Informal settlement, E. coli, Kenya

*Correspondence: sylvia.omulo@wsu.edu

1 Paul G. Allen School for Global Animal Health, Washington State University, Pullman, WA, USA

Full list of author information is available at the end of the article

\section{Introduction}

Numerous organizations have called attention to the increasing prevalence of antimicrobial resistance (AMR) worldwide [1]. Efforts to preserve the efficacy of existing antibiotics have focused predominantly, if not exclusively, on improving prescription guidelines and compliance original author(s) and the source, provide a link to the Creative Commons licence, and indicate if changes were made. The images or other third party material in this article are included in the article's Creative Commons licence, unless indicated otherwise in a credit line to the material. If material is not included in the article's Creative Commons licence and your intended use is not permitted by statutory regulation or exceeds the permitted use, you will need to obtain permission directly from the copyright holder. To view a copy of this licence, visit http://creativecommons.org/licenses/by/4.0/. The Creative Commons Public Domain Dedication waiver (http://creativeco mmons.org/publicdomain/zero/1.0/) applies to the data made available in this article, unless otherwise stated in a credit line to the data. 
to reduce unnecessary antibiotic use. This "stewardship focus" is led by high-income countries in North America, Europe, and Oceania where robust healthcare infrastructure and regulatory frameworks are present. Nevertheless, these countries comprise only $15 \%$ of the world's population and are poorly representative of the global burden of infectious disease [2-4].

In 2013 the United Nations Human Settlements Program estimated that a quarter of the world's urban population lived in slums [5]; informal settlements characterized by high population density, poor sanitation and lack of consistent access to clean water. These characteristics promote the spread of infectious diseases and the demand for antibiotics, when available [6-8], and support the observations by Collignon et al. [9] that countries with poor infrastructure, poor governance and limited public health expenditures have a higher prevalence of antimicrobial-resistant bacteria compared with countries that rank better by these metrics. Consequently, while encouraging antibiotic stewardship might be important for limiting AMR, it may not be an effective strategy for communities where exposure to unhygienic conditions and rapid spread of pathogens overwhelm individual decisions regarding antibiotic use, whether within or outside the healthcare system.

We assessed the relationship between sanitation, antibiotic use, and antimicrobial resistance in Kibera. We surmise that socio-economic and environmental determinants likely impact both antibiotic use and antimicrobial resistance in Kibera and similar impoverished communities.

\section{Methods}

\section{Study area}

This study involved two villages in Kibera-Soweto and Gatwekera. Kibera, an informal settlement in NairobiKenya, is one of the largest slums in Africa [5]. Residents of Kibera suffer a high incidence of infectious disease, including diarrhea, which is compounded by a lack of safe and hygienic sanitation facilities [3, 10]. Correspondingly, antibiotic use is common; a 2016 survey showed that $87 \%$ of Kibera respondents reported having used an antibiotic in the 12-month period preceding the survey [11]. Soweto and Gatwekera have a population density of $55,000-84,000$ persons $/ \mathrm{km}^{2}$ [12] and are part of a population-based infectious disease surveillance (PBIDS) program. This program collects household and clinic data on common infectious disease syndromes for an enumerated population of $\sim 25,000$ individuals and is operated and supported jointly by the Kenya Medical Research Institute-KEMRI, Carolina for Kibera, and the U.S. Centers for Disease Control and Prevention-CDC [3].

\section{Study design}

\section{Household selection}

Two-hundred households were randomly selected from a census of 5320 households that participate in PBIDS. Selection was restricted to households with at least one adult ( $\geq 18$ years) and one child ( $\leq 5$ years), and to one household per housing block. This strategy maximized variation in our sample; adults and children vary in their antibiotic use and sanitation practices while household locations determine access to antibiotic sources and sanitation facilities. Within each household, two members were invited to enroll into the study; an adult with knowledge of household sanitation and healthcare practices, and the youngest of children aged $\leq 5$ years. Residents who were routinely engaged in daytime activities (e.g., work or school) outside the household were excluded from enrollment to minimize loss to follow-up.

\section{Survey data collection}

Households were visited once every two weeks, for a total of nine study visits, between August 2015 and January 2016. This period encompassed a dry (August-October) and wet (November-January) season. Local monthly average rainfall $(\mathrm{mm})$ was retrieved from the v7 Tropical Rainfall Measuring Mission Multi-Satellite Precipitation Analysis algorithm [13]. At each visit, data on self-reported sanitation- (Additional file 1) and antibiotic use practices (Additional file 2) during the two weeks preceding each visit were recorded. The sanitation survey tool was modified from a pre-tested questionnaire [14] that expanded upon a Joint Monitoring Programme tool for Water Supply and Sanitation [15]. The antibiotic use survey tool was developed and piloted in select households within Kibera (excluded from the main study). This tool addressed antibiotic types and sources, reasons for antibiotic use, dose completion and duration of use. During each visit, household respondents were reminded to retain used medication packages for subsequent data abstraction. Observational data for household drinking water storage containers, toilet types and hand-washing stations were collected at enrollment, and at visits 8 and 9.

\section{Sample collection}

Up to five samples were collected from each household at each visit, including a stool sample and a hand-swab from the two enrolled respondents, and a water sample from the household's drinking water reserve. Households were trained on acceptable stool collection and packaging methods during the enrollment visit. Thereafter, a stool collection kit was supplied on the eve of each follow-up visit to enable participants to collect fresh stool 
on the day of the visit. Hand swabs and water samples were collected by field officers on the day of the visit. To collect a hand-swab, a sterile polyester-tipped applicator (Puritan, Guilford, ME) was moistened in sterile phosphate-buffered saline (PBS) and rolled over the palm of a participant's right hand, in between the fingers and under the nails. The swab was then immersed into a vial containing $1 \mathrm{~mL}$ of sterile PBS, capped and labeled. Water samples were collected by asking the adult respondent to provide a cup of drinking water, which was subsequently transferred into two sterile $50 \mathrm{~mL}$ tubes. All samples were maintained in iceboxes until transported to a KEMRI laboratory located within Kibera for processing within $6 \mathrm{~h}$ of collection.

\section{Sample processing methods}

Stool samples were processed by adding $1 \mathrm{~g}$ of sample to 9-mL aliquots of PBS and preparing up to six tenfold serial dilutions of the suspension. The $10^{-6}$ dilution (50 $\mu \mathrm{L})$ was spread onto 90-mm MacConkey (Mac) agar plates (Becton Dickinson, Fair Lawn, NJ) using 10-15 sterilized 3-mm glass beads. Hand swabs in PBS were first mixed to achieve a homogeneous suspension. Half $(500 \mu \mathrm{L})$ of the suspension was then transferred to sterile microtubes and centrifuged at $2700 \times g$ for $15 \mathrm{~min}$. After drawing out $450 \mu \mathrm{L}$ of the supernatant, the remaining sediment suspension was spread onto 90-mm Mac agar plates using sterile beads. Water samples were centrifuged at $2700 \times g$ for $30 \mathrm{~min}$ and $1 \mathrm{~mL}$ of the sediment was transferred into a $1.5 \mathrm{~mL}$ microcentrifuge tube for further centrifugation at $9800 \times g$ for $10 \mathrm{~min}$. The pellet was re-suspended in $200 \mu \mathrm{L}$ of PBS and $50 \mu \mathrm{L}$ was spread onto $90 \mathrm{~mm}$ Mac agar plates. All plates were incubated overnight $(18-24 \mathrm{~h})$ at $37{ }^{\circ} \mathrm{C}$ in a stationary incubator. The total number of presumptive $E$. coli colonies for each plate was enumerated and used to calculate the number of colony-forming units (CFU) per gram (stool). Hand swabs and water samples were only used to determine presence or absence of resistant bacteria; these were not enumerated. No antibiotics were added to any of the agar plates.

Twelve presumptive E. coli isolates [16] were collected from each adult and child sample to total 24 per household. Collection was done using sterile toothpicks. Isolates were transferred into individual wells of 96-well microtiter plates pre-filled with $100 \mu \mathrm{L}$ of Luria-Bertani broth (Becton Dickinson, Fair Lawn, NJ). The microtiter plates were incubated for $18-24 \mathrm{~h}$. Glycerol [15\% (v/v)] was added to each well and plates were frozen at $-20{ }^{\circ} \mathrm{C}$ until tested for antibiotic susceptibility.

Prior to testing, a replicate of the original microtiter plate was prepared. A sterile 96-pin replicator was used to transfer $\sim 2 \mu \mathrm{L}$ of thawed culture into sterile microtiter plates containing $100 \mu \mathrm{L}$ per well of Luria-Bertani broth. The plates were incubated overnight at $37{ }^{\circ} \mathrm{C}$. A breakpoint assay was conducted by transferring approximately $2 \mu \mathrm{L}$ of thawed culture onto $150-\mathrm{mm}$ Mac agar plates containing one of nine antibiotics $[32 \mu \mathrm{g} / \mathrm{ml}$ ampicillin, Amp; $8 \mu \mathrm{g} / \mathrm{ml}$ ceftazidime, Caz; $32 \mu \mathrm{g} / \mathrm{ml}$ chlorampheni$\mathrm{col}$, Chl; $4 \mu \mathrm{g} / \mathrm{ml}$ ciprofloxacin, Cip; $64 \mu \mathrm{g} / \mathrm{ml}$ kanamycin, Kan; $16 \mu \mathrm{g} / \mathrm{ml}$ streptomycin, Str; $512 \mu \mathrm{g} / \mathrm{ml}$ sulfamethoxazole, Sul; $16 \mu \mathrm{g} / \mathrm{ml}$ tetracycline, Tet; and $16 \mu \mathrm{g} / \mathrm{ml}$ trimethoprim, Tmp (all from Sigma, St. Louis, MO)]. A reference plate (Mac without antibiotic) was prepared for each 96-well plate to confirm cell viability. Isolates were either scored resistant (visible growth) or susceptible (no growth). Partial growth (satellite colonies) relative to the reference plate was considered susceptible. For quality control, 248 presumptive E. coli isolates were subjected to biochemical confirmation using Triple Sugar Iron agar (BD Difco ${ }^{\mathrm{TM}}$, Sparks, MD) and Motility Indole Ornithine medium (BD Difco ${ }^{\mathrm{TM}}$, Sparks, MD). Of these 15 were randomly selected isolates for further confirmation using the API $^{\circledR} 20$ E test kit (bioMérieux ${ }^{\circledR}$ sa, Marcy-l'Etoile, France) following manufacturer's instructions.

\section{Data management and analysis}

Household survey data were checked for accuracy and completeness within a day of collection and were compiled in a Microsoft Access database (Microsoft, Redmond, WA). Sample data were managed in Microsoft Excel (Microsoft, Redmond, WA). The main outcomes of interest were "load of resistance" (stool samples only), prevalence of resistance and number of resistance patterns. The load of resistance was calculated as a product of the prevalence of resistance (proportion of stool isolates resistant to each antibiotic) and the quantified E. coli CFU. This measure was chosen to reflect different reservoir "sizes" of resistant bacteria and to provide greater analytical power to detect modest changes in colonization that may not have been detectable with prevalence values. Load data were $\log _{10}$-transformed and analyzed as continuous variables. Linear mixed-effects models fit by the restricted maximum likelihood lme4 package in $\mathrm{R}$ [17] were used to identify predictors for the $\operatorname{load}\left(\log _{10}\right)$ of resistant $E$. coli in stool samples. Separate models were constructed to predict household-level (adult and child samples) and individual-level (adult or child samples) AMR load. Antibiotic use, water, sanitation, and hygienerelated variables were tested as the main predictors for the carriage of antibiotic resistant $E$. coli. Demographic and environmental variables were additional predictors.

Effects due to household respondents were assumed to be constant across households. Consequently, only a household-specific random intercept (Household ID) was included in household-level models, and an 
individual-specific random intercept (Respondent ID) in individual-level models. This allowed us to account for variations due to repeated sampling of households and individuals, respectively. Each fixed effect was regressed independently against household or individual AMR load, applying the appropriate random intercept. Variables with $P<0.2$ in two or more univariable models were included in the multivariable regression analyses. To avert modeling problems resulting from collinearity, a Pearson's correlation coefficient was used to identify correlated variables $(r \geq 0.7)$ after which one of a pair of correlated variables was removed. Variables with $P<0.05$ in the multivariable analysis were considered significant predictors of the load of resistant $E$. coli.

\section{Results}

\section{Survey respondents}

Eighty-one percent (81\%) of the 200 enrolled households participated in seven of the nine visits. Household participation dipped in visits 8 (64\%) and 9 (58\%) because some study respondents traveled elsewhere for holiday festivities (Fig. 1). In total, 1516 household interview responses were collected and analyzed. Our selection criteria resulted in a predominantly female adult sample (97\%) constituting primarily the mothers of the enrolled children (Table 1).

\section{Antibiotic use}

Ninety-seven (48.5\%) of the 200 households reported an antibiotic use episode in at least one visit over the

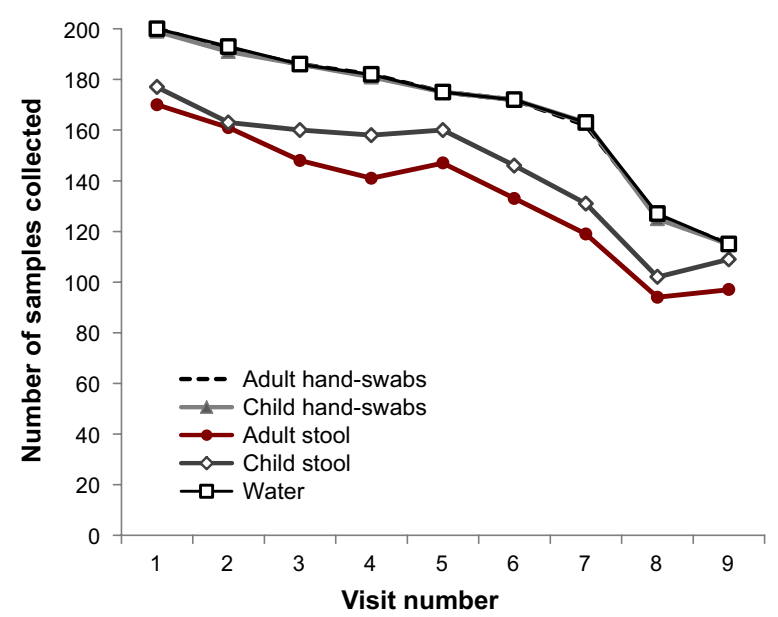

Fig. 1 Distribution of 6674 samples (2843 hand swabs, 2341 stool, 1490 water) collected from 200 study households over a 5-month study period. Sample collection on visits 8 and 9 was impacted by temporary migration of study respondents to other areas for holiday festivities. Visits 1 to 8 occurred between August and December 2015 while Visit 9 occurred in January 2016

\begin{tabular}{llll}
$\begin{array}{l}\text { Table } 1 \text { Baseline characteristics } \\
\text { respondents and households }(\mathbf{n = 2 0 0 )}\end{array}$ & & participating \\
\hline & Counts (\%) & Mean (range) & SD \\
\hline Respondent characteristics & $194(97.0)$ & - & - \\
Female & $188(94.0)$ & - & - \\
Mother of enrolled child & - & $1.6(0-5)$ & 1.1 \\
Age of enrolled child (years) & - & $28.7(18-68)$ & 7.8 \\
Age of enrolled adult (years) & & & \\
Mother's level of education & & - & - \\
No education & $11(5.5)$ & - & - \\
Primary school & $119(59.5)$ & - & - \\
High school/vocational training & $61(30.5)$ & - & - \\
College/university & $9(4.5)$ & - & 1.9 \\
Household population structure & & & 1.1 \\
Household size & - & $5.2(2-13)$ & 0.6 \\
Members $\geq 18$ years & - & $2.4(1-6)$ & 1.6 \\
Members $\leq 5$ years & - & $1.4(1-4)$ & \\
School-going children & - & $1.8(0-9)$ &
\end{tabular}

Frequencies and percentages are provided for categorical values while mean and standard deviation (SD) are provided for continuous values

5-month period. This accounted for 144 episodes, i.e., reported case of antibiotic use by the enrolled adult, enrolled child, and/or other household member, and a total of 190 antibiotic "doses". Enrolled children had five times the number of episodes reported by enrolled adults (96 vs. 19) and three times that by other household members (96 vs. 29). Episodes by enrolled children represented $67 \%(96 / 144)$ of household antibiotic use episodes. Fifteen different antibiotics were reported over the study period, $53 \%$ of which were beta-lactam antibiotics. Amoxicillin was the most used antibiotic within the household (50\%; 95/190), followed by ampicillin (12\%; $22 / 190)$, cotrimoxazole $(10 \% ; 19 / 190)$, erythromycin and metronidazole (each 7\%; 14/190). Enrolled children commonly used amoxicillin $(56 \% ; 70 / 125)$ and cotrimoxazole (12\%; 15/125); Fig. 2. Data collectors confirmed the identities of antibiotics in $74 \%$ of reported instances of use.

\section{Water, sanitation, and hygiene}

Most households (92\%) accessed water for their daily household needs from protected sources, and 81\% spent $<15$ min to make a return trip to the main water source (Table 2). Observational data confirmed that of the $166(83 \%)$ households that stored drinking water within the household at baseline, $78.3 \%$ used storage containers with narrow openings $(<3 \mathrm{~cm})$, and $89.6 \%$ secured their storage containers with lids. Less than half of households (44\%) reported treating their water. More households reported water unavailability at enrollment than in subsequent visits (53\% vs. 15\%). No household 


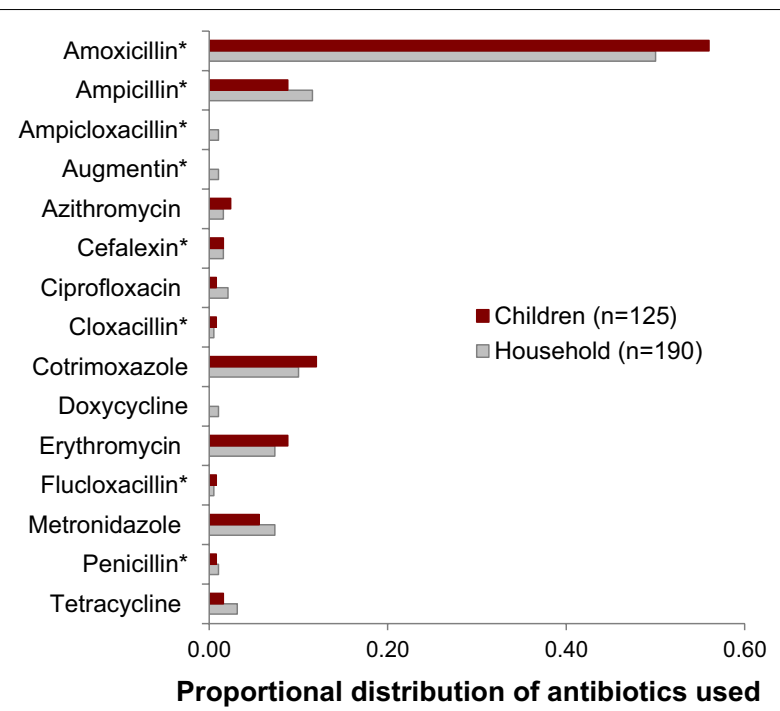

Fig. 2 Aggregate distribution of antibiotic use by households and by enrolled children over the study period (includes second antibiotic if use was reported). Asterisk* indicates beta-lactam antibiotic

owned a toilet; the majority relied on public toilets. The type of toilet used varied by time of day, particularly for flush toilets (48\% during the day vs. $7 \%$ at night) and buckets/plastic bags ( $0 \%$ during the day vs. $35 \%$ at night). Handwashing after toilet use was reportedly high $(>75 \%)$ although $<50 \%$ of households reported having a designated hand-washing station. On average, $54 \%$ of households reported that the enrolled child spent 1 to $12 \mathrm{~h}$ outside the household, primarily playing within the household periphery (87\%). Of these, $49 \%$ also indicated that the child ate soil from the household compound. Household responses on water, sanitation and hygiene questions were consistent between the enrollment visit and subsequent visits except for the question regarding water unavailability i.e. $53 \%$ vs. $15 \%$ (Table 2 ).

\section{Antimicrobial resistance}

Presumptive E. coli were isolated from $99.0 \%$ of stool $(\mathrm{n}=2341), 12.1 \%$ hand $(\mathrm{n}=2843)$ and $9.8 \%$ of water $(\mathrm{n}=1490)$ samples. Phenotypic tests for 248 isolates confirmed that our selection criteria for $E$. coli was reliable (99.2\% accuracy). Isolates (stool $n=27,451$, hand swabs $n=3639$, water $n=2952$ ) were tested against nine antibiotics from seven antibiotic classes. Of these, $23,981(87.4 \%)$ stool isolates, $3020(83.0 \%)$ hand swab isolates and 2354 (79.7\%) water isolates were resistant to at least one antibiotic; $80 \%$ percent of all presumptive $E$. coli isolates were resistant to $\geq 3$ antibiotic classes. The prevalence of resistance to ampicillin, streptomycin, sulfamethoxazole, tetracycline, and trimethoprim was $>15 \%$ across all sample types and $>50 \%$ among stool samples.
Resistance to ceftazidime, chloramphenicol, ciprofloxacin, and kanamycin was $<15 \%$ across all specimen types (Fig. 3).

A total of 148 unique resistance profiles were identified from the isolates collected in this study. A "penta-resistant" profile AmpStrSulTetTmp predominated in stool isolates $(31.3 \%)$ and hand swabs $(19.6 \%)$, while SulTmp was the most abundant in isolates from water $(20.4 \%$; Additional file 3). Half of all stool samples had two or three resistance profiles of varying antibiotic combinations. The distribution of unique resistance phenotypes in stool samples was similar for individuals that reported using antibiotics (users) and those that did not (nonusers); Fig. 4. Pan-resistant isolates (resistant to the nine antibiotics tested) were identified in one adult and one child sample from two different households. These individuals reported not having used antibiotics in the two weeks preceding their sample collection.

The average load of resistant $E$. coli in stool ranged between $1.4 \times 10^{7}$ and $1.5 \times 10^{8} \mathrm{CFU} / \mathrm{g}$ for the highly prevalent resistance phenotypes (Amp, Str, Sul, Tet and Tmp), and between $0.7 \times 10^{1}$ and $1.3 \times 10^{2} \mathrm{CFU} / \mathrm{g}$ for low-prevalence phenotypes (Caz, Chl, Cip and Kan). The distribution of resistant E. coli in adult and child stool samples was similar although on average, children had marginally higher loads of ampicillin and chloramphenicol-resistant E. coli (Fig. 5).

\section{Predictors of antimicrobial resistance}

Univariable analyses identified water, sanitation, and antibiotic use variables as potential predictors $(P<0.2)$ of both prevalence and load of resistant $E$. coli at household and individual levels. When these predictors were added to multivariable regression models, the level of significance $(P<0.05)$ varied depending on the antibiotic tested, and the level of analysis i.e. household or individual (Tables 3, 4, 5). Antibiotic use within the household was not a significant risk factor for resistance to any of the nine antibiotics tested in adults and was only associated with resistance to two antibiotics in children (Sul, $\beta=0.46$ log-increase in load; Tmp, $\beta=0.42$; Table 5).

Enrolled children eating soil $(\beta=0.27$ to $0.80 \mathrm{log}$ increase) and presence of a common hand-washing station within the housing block ( $\beta=0.22$ to 0.51 ) were both associated with increased load of antimicrobial-resistant E. coli at both household and individual levels. The presence of a common hand-washing station was associated with increased load at the level of household (Tmp, Sul, Tet, Amp, $\beta=0.22$ to 0.47 ), among adults (Tmp, Sul, Tet, Amp, $\beta=0.29$ to 0.51 ), and children (Sul, Amp, $\beta=0.35$ to 0.45$)$.

Rainfall was the single best predictor for decreased load (1.19 to $3.26 \log )$ of antibiotic-resistant E. coli at the 
Table 2 Proportion of household responses (mean and 95\% confidence interval) for questions regarding water, sanitation, and hygiene-related practices at enrollment (V1) and over nine sampling visits

\begin{tabular}{|c|c|c|c|c|c|c|c|c|}
\hline \multicolumn{3}{|l|}{ Water } & \multicolumn{3}{|l|}{ Sanitation } & \multicolumn{3}{|l|}{ Hygiene } \\
\hline & V1 & Mean $[95 \% \mathrm{Cl}]$ & & V1 & Mean $[95 \% \mathrm{Cl}]$ & & V1 & Mean $[95 \% \mathrm{Cl}]$ \\
\hline \multicolumn{3}{|l|}{ Type of water source } & \multicolumn{3}{|c|}{ Type of toilet used during daytime } & \multicolumn{3}{|c|}{$\begin{array}{l}\text { Washed hands after urination only [last } 3 \text { toilet } \\
\text { visits] }\end{array}$} \\
\hline Private-protected & 0.40 & $0.36[0.29,0.43]$ & Flush toilet & 0.45 & $0.48[0.46,0.50]$ & 1 out of 3 events & 0.16 & $0.09[0.06,0.12]$ \\
\hline Public-protected & 0.52 & $0.61[0.53,0.69]$ & Ventilated-improved pit & 0.03 & $0.04[0.03,0.05]$ & 2 out of 3 events & 0.20 & $0.14[0.10,0.18]$ \\
\hline Private-unprotected & 0.01 & $0.01[0.00,0.02]$ & Pit with slab & 0.41 & $0.34[0.32,0.36]$ & All 3 events & 0.64 & $0.77[0.70,0.84]$ \\
\hline Public-unprotected & 0.09 & $0.03[-0.01,0.07]$ & Traditional pit latrine $^{d}$ & 0.12 & $0.13[0.12,0.14]$ & $\begin{array}{l}\text { 'Washed with soapc } \\
\text { [yes] }\end{array}$ & 0.80 & $0.83[0.79,0.87]$ \\
\hline \multicolumn{3}{|c|}{ Time taken to go, collect water, and return } & \multicolumn{3}{|c|}{ Households sharing same daytime toilet facility } & \multicolumn{3}{|c|}{ Washed hands after defecation [last 3 toilet visits] } \\
\hline 5 min or less & 0.28 & $0.19[0.16,0.22]$ & $1-10$ & 0.21 & $0.20[0.19,0.21]$ & 1 out of 3 events & 0.08 & $0.02[0.00,0.04]$ \\
\hline $5-9 \min$ & 0.34 & $0.44[0.39,0.49]$ & $11-50$ & 0.30 & $0.26[0.24,0.28]$ & 2 out of 3 events & 0.18 & $0.10[0.06,0.14]$ \\
\hline $10-14 \min$ & 0.18 & $0.18[0.15,0.21]$ & $51-100$ & 0.44 & $0.33[0.23,0.43]$ & All 3 events & 0.74 & $0.88[0.83,0.93]$ \\
\hline$\geq 15 \min$ & 0.20 & $0.19[0.16,0.22]$ & $>100$ & 0.06 & $0.21[0.11,0.31]$ & $\begin{array}{l}\text { Washed with soap } \\
\text { [yes] }\end{array}$ & 0.74 & $0.90[0.85,0.95]$ \\
\hline \multicolumn{3}{|c|}{ Water unavailable at source in the last 14 days } & \multicolumn{3}{|c|}{ Frequency of toilet cleaning during the last 14 days } & \multicolumn{3}{|c|}{$\begin{array}{l}\text { Washed hands before feeding baby [last } 3 \text { feeding } \\
\text { events] }\end{array}$} \\
\hline $1-6$ days & 0.44 & $0.13[0.04,0.22]$ & Daily & 0.47 & $0.56[0.53,0.59]$ & 1 out of 3 events & 0.09 & $0.05[0.04,0.06]$ \\
\hline $7-14$ days & 0.08 & $0.02[0.01,0.03]$ & Alternate days & 0.21 & $0.16[0.13,0.19]$ & 2 out of 3 events & 0.23 & $0.12[0.07,0.17]$ \\
\hline \multicolumn{3}{|c|}{ Methods used to make water safer to drink ${ }^{b}$} & Occasionally & 0.26 & $0.23[0.22,0.24]$ & All 3 events & 0.67 & $0.83[0.77,0.89]$ \\
\hline Boiling & 0.65 & $0.52[0.47,0.57]$ & \multicolumn{3}{|c|}{ Location of daytime toilet facility } & $\begin{array}{l}\text { Washed with soap } \\
\text { [yes] }\end{array}$ & 0.69 & $0.86[0.81,0.91]$ \\
\hline Chemical cleansers & 0.54 & $0.62[0.57,0.67]$ & Within $\mathrm{HH}$ compound & 0.30 & $0.32[0.31,0.33]$ & \multicolumn{3}{|c|}{ Location of hand-washing station } \\
\hline \multicolumn{3}{|c|}{ Frequency of water treatment in last 14 days ${ }^{b}$} & Outside HH compound & 0.70 & $0.68[0.67,0.69]$ & $\begin{array}{l}\text { Within household } \\
\text { compound }\end{array}$ & 0.25 & $0.25[0.19,0.31]$ \\
\hline Every collection & 0.71 & $0.75[0.70,0.80]$ & \multicolumn{3}{|c|}{ Type of toilet used during the night } & Around kitchen area & 0.32 & $0.45[0.41,0.49]$ \\
\hline Occasionally & 0.29 & $0.25[0.20,0.30]$ & Flush toilet & 0.16 & $0.07[0.04,0.1]$ & $\begin{array}{l}\text { Elsewhere [excl. } \\
\text { kitchen/toilet] }\end{array}$ & 0.46 & $0.37[0.30,0.44]$ \\
\hline \multicolumn{3}{|c|}{ Last household water treatment ${ }^{\mathrm{b}}$} & Ventilated-improved pit & 0.03 & $0.04[0.03,0.05]$ & Nonspecific & 0.61 & $0.59[0.56,0.62]$ \\
\hline Today/yesterday & 0.21 & $0.26[0.23,0.29]$ & Pit with concrete slab & 0.39 & $0.37[0.36,0.38]$ & \multicolumn{3}{|c|}{ Time spent by the enrolled child outside household } \\
\hline 2-6 days ago & 0.67 & $0.63[0.58,0.68]$ & Traditional pit latrine & 0.12 & $0.13[0.12,0.14]$ & $1-2 \mathrm{~h}$ & 0.15 & $0.14[0.13,0.15]$ \\
\hline \multirow[t]{7}{*}{$\geq 7$ days ago } & 0.11 & $0.11[0.08,0.14]$ & Bucket/plastic bags & 0.29 & $0.35[0.32,0.38]$ & $3-4 h$ & 0.21 & $0.19[0.16,0.22]$ \\
\hline & & & Open areas around $\mathrm{HH}$ & 0.02 & $0.03[0.02,0.04]$ & $5+h$ & 0.30 & $0.21[0.16,0.26]$ \\
\hline & & & & & & \multicolumn{3}{|c|}{ Places where the enrolled child spends time } \\
\hline & & & & & & $\begin{array}{l}\text { Plays in school com- } \\
\text { pound }\end{array}$ & 0.00 & $0.01[-0.03,0.05]$ \\
\hline & & & & & & $\begin{array}{l}\text { Within household } \\
\text { environment }\end{array}$ & 0.93 & $0.87[0.83,0.91]$ \\
\hline & & & & & & $\begin{array}{l}\text { Relative in another } \\
\text { household }\end{array}$ & 0.07 & $0.12[0.09,0.15]$ \\
\hline & & & & & & $\begin{array}{l}\text { Enrolled child eats soil } \\
\text { [yes] }\end{array}$ & 0.55 & $0.49[0.37,0.61]$ \\
\hline
\end{tabular}

Two hundred households were enrolled

$H H$ household

${ }^{a}$ A protected source prevents water contamination by the environment e.g., a source covered with a concrete slab or a completely covered tank

${ }^{\text {b }}$ Applies only to households that reported treating water (mean $=44 \%$ )

c Applies to those who reported washing hands mean $=80 \%$ (urination), $98 \%$ (defecation) or $87 \%$ (feeding baby)

d Single pit covered by a wooden, earthen, or concrete slab with a drop hole

level household (Tmp, Str, Amp, $\beta=-1.19$ to $-2 \cdot 56$; Table 2), among adults (Tmp, Amp, $\beta=-1 \cdot 79$ to $-3 \cdot 26$;
Table 3) and children (Amp, $\beta=-2 \cdot 02$ ) levels (Table 5). Household elevation (10 m increments) was associated 


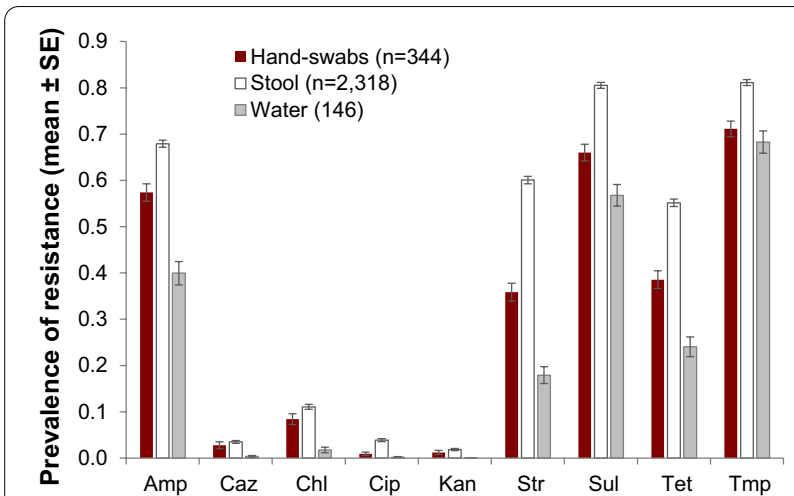

Fig. 3 Prevalence of resistant E. coli (mean and standard error) in stool, hand swabs, and water samples. Stool and hand swab values are pooled estimates for adults and children. Amp, ampicillin; Caz, ceftazidime, Chl, chloramphenicol; Cip, ciprofloxacin; Kan, kanamycin, Str, streptomycin; Sul, sulfamethoxazole; Tet, tetracycline; Tmp, trimethoprim

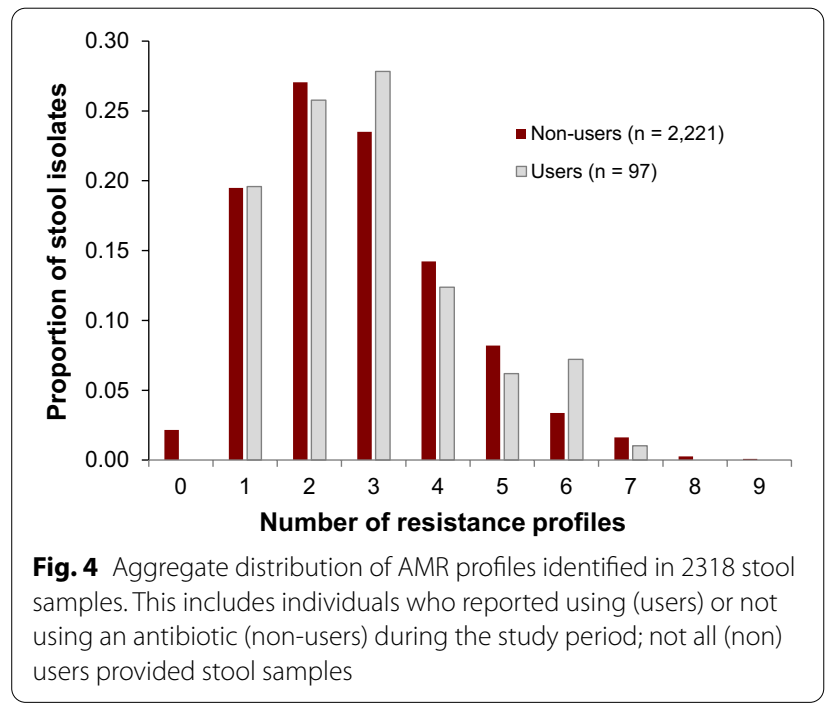

with slight load reductions among children (Amp, Sul, Tri, $\beta=-0 \cdot 10)$.

\section{Discussion}

During a 2016 survey of antibiotic use in Kibera, 87\% of respondents reported using an antibiotic in the preceding 12 months [11]. In this study, half of the enrolled households reported using an antibiotic within a 5-month period, consistent with the high burden of disease reported in this community $[3,10,18]$. A World Health Organization survey of 12 low- and middle-income countries found that $35-76 \%$ of respondents had used antibiotics in the previous six months [19] in contrast to lower levels of use reported in wealthier countries

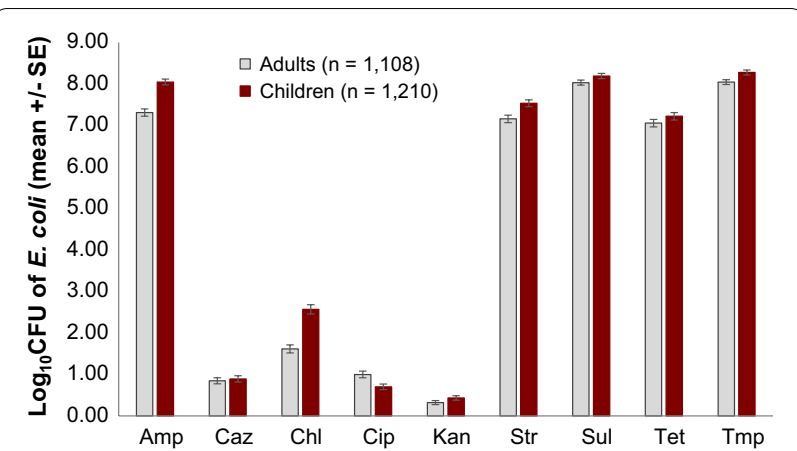

Fig. 5 Load of resistant E. coli (mean and standard error) in adult and child stool samples. Amp, ampicillin; Caz, ceftazidime, Chl, chloramphenicol; Cip, ciprofloxacin; Kan, kanamycin, Str, streptomycin; Sul, sulfamethoxazole; Tet, tetracycline; Tmp, trimethoprim

[20]. Nevertheless, we found no consistent association between the reported use of antibiotics in our study and the abundance, prevalence, or diversity of antibioticresistant $E$. coli in this population despite the common use of oral formulations (Fig. 2) that should selectively favor antibiotic-resistant intestinal E. coli.

The lack of clear association between antibiotic use and prevailing levels of AMR does not imply that there is no causal relationship, rather that in this community, carriage of resistant bacteria changes little in response to incremental changes in antibiotic use. Instead, our analysis identified environmental and sanitation variables as predictive for the abundance of antibiotic-resistant E. coli in Kibera households (Table 3) and among individual household members (Tables 4,5). Poor sanitation and environmental contamination likely play a dual role of increasing disease burden and demand for antibiotics (keeping selective pressure high at the community level), while also disseminating antibiotic-resistant bacteria within and between households. For example, approximately $10 \%$ of all hand swabs and water samples confirmed contamination with resistant bacteria (Fig. 3).

Sanitation-related factors have been implicated in the spread of infectious diseases [21-24], child malnutrition and/or stunting [25], cognitive deficiencies in children, and poor school attendance [21, 26]. Their role in the spread of antibiotic-resistant bacteria has also been postulated [27, 28]. Households in our study had no toilets within the premises, but generally had access to some form of public toilet facility, particularly during daytime [15]. Nevertheless, these public toilets were shared by at least 10 other households. Personal security concerns markedly reduces use of sanitation facilities at night [29], forcing households to improvise by using buckets, plastic bags ("flying toilets") or open spaces outside the 
Table 3 Multivariable regression analysis for antimicrobial resistance load ( $\left.\log _{10} \mathrm{CFU}\right)$ at the household level

\begin{tabular}{|c|c|c|c|c|c|}
\hline Predictor & $\begin{array}{l}\text { Ampicillin } \\
\beta[95 \% \mathrm{Cl}]\end{array}$ & $\begin{array}{l}\text { Streptomycin } \\
\beta[95 \% \mathrm{Cl}]\end{array}$ & $\begin{array}{l}\text { Sulfamethoxazole } \\
\beta[95 \% \mathrm{Cl}]\end{array}$ & $\begin{array}{l}\text { Tetracycline } \\
\beta[95 \% \mathrm{Cl}]\end{array}$ & $\begin{array}{l}\text { Trimethoprim } \\
\beta[95 \% \mathrm{Cl}]\end{array}$ \\
\hline \multicolumn{6}{|l|}{ Night toilet type } \\
\hline Ventilator improved pit & $0.46[-0.34,1.26]$ & $0.32[-0.59,1.23]$ & $0.07[-0.59,0.74]$ & $-0.27[-1.22,0.67]$ & $-0.06[-0.69,0.57]$ \\
\hline Pit with concrete slab & $0.49[0.00,0.99]$ & $0.50[-0.06,1.07]$ & $0.13[-0.28,0.54]$ & $-0.13[-0.71,0.46]$ & $-0.04[-0.43,0.35]$ \\
\hline Traditional pit latrine $\mathrm{a}^{\mathrm{a}}$ & $0.03[-0.58,0.63]$ & $0.25[-0.44,0.94]$ & $-0.07[-0.57,0.43]$ & $-0.79[-1.51,-0.08]$ & $-0.07[-0.54,0.40]$ \\
\hline Bucket/plastic & $0.26[-0.23,0.75]$ & $0.23[-0.32,0.79]$ & $-0.06[-0.47,0.34]$ & $-0.62[-1.19,-0.04]$ & $-0.24[-0.62,0.15]$ \\
\hline No facilities/open field & $0.46[-0.29,1.22]$ & $0.03[-0.82,0.88]$ & $-0.02[-0.64,0.60]$ & $-0.71[-1.59,0.18]$ & $-0.64[-1.23,-0.04]$ \\
\hline Handwashing with soap & $0.20[0.01,0.40]$ & $0.21[-0.01,0.43]$ & $0.07[-0.09,0.23]$ & $0.19[-0.03,0.42]$ & $0.10[-0.06,0.25]$ \\
\hline \multicolumn{6}{|c|}{ Handwashing facility location } \\
\hline Toilet within premises & $0.14[-0.15,0.43]$ & $0.13[-0.19,0.46]$ & $0.10[-0.13,0.34]$ & $0.25[-0.09,0.59]$ & $0.17[-0.05,0.4]$ \\
\hline Elsewhere on premises ${ }^{b}$ & $0.47[0.20,0.73]$ & $0.28[-0.02,0.58]$ & $0.35[0.13,0.57]$ & $0.36[0.05,0.67]$ & $0.22[0.01,0.43]$ \\
\hline No designated place & $-0.28[-0.55,-0.02]$ & $-0.13[-0.44,0.17]$ & $0.04[-0.18,0.26]$ & $0.26[-0.05,0.58]$ & $-0.21[-0.42,0.00]$ \\
\hline \multicolumn{6}{|l|}{ Enrolled child } \\
\hline Time spent outside (h) & $0.00[-0.05,0.05]$ & $-0.01[-0.08,0.05]$ & $0.01[-0.03,0.06]$ & $0.03[-0.03,0.09]$ & $0.00[-0.04,0.04]$ \\
\hline Eats soil & $0.51[0.26,0.77]$ & $0.39[0.10,0.68]$ & $0.27[0.06,0.48]$ & $0.54[0.24,0.84]$ & $0.28[0.08,0.48]$ \\
\hline Rainfall (per mm) & $-2.56[-3.60,-1.52]$ & $-1.23[-2.40,-0.06]$ & $-0.57[-1.42,0.28]$ & $1.18[-0.03,2.40]$ & $-1.19[-2.00,-0.37]$ \\
\hline \multicolumn{6}{|l|}{ Mother's education level } \\
\hline Primary school & $-0.52[-1.17,0.14]$ & $-0.72[-1.48,0.05]$ & $-0.25[-0.82,0.32]$ & $-0.11[-0.91,0.68]$ & $0.02[-0.50,0.53]$ \\
\hline High school & $-0.87[-1.58,-0.16]$ & $-0.91[-1.73,-0.08]$ & $-0.29[-0.90,0.32]$ & $-0.26[-1.11,0.60]$ & $0.02[-0.53,0.57]$ \\
\hline College & $-0.93[-1.90,0.05]$ & $-1.40[-2.53,-0.26]$ & $-0.32[-1.16,0.52]$ & $-0.70[-1.88,0.47]$ & $0.19[-0.57,0.95]$ \\
\hline Respondent age (years) & $-0.02[-0.03,-0.02]$ & $-0.01[-0.02,0.00]$ & $0.00[-0.01,0.00]$ & $0.00[-0.01,0.00]$ & $-0.01[-0.01,0.00]$ \\
\hline
\end{tabular}

Only variables with $P<0.2$ in the univariable mixed-effects model were included in the multivariable model. Regression estimates for increasing or decreasing antimicrobial load (positive or negative $\beta$ coefficients, respectively) and $95 \%$ confidence intervals with $P<0.05$ are shown in bold. Only variables with significant values are shown. See Additional file 4 for complete table

a Single pit covered by a wooden, earthen or concrete slab with a drop hole

b Other than at a toilet facility or the household kitchen

household to dispose of feces. These alternative disposal options have been documented by others $[14,26]$ and contribute to significant environmental contamination [30].

Fecal environmental contamination likely explains why the variable "children eating soil" was a significant predictor for increased individual and household AMR load. This environmental connection is consistent with the negative association between the load of antibioticresistant E. coli in stool samples and rainfall, as runoff can dilute or remove fecal sources of bacteria in the environment (also consistent with the observed elevation correlation for AMR prevalence in isolates from children), or discourage outdoor activities and thus reduce contact with contaminated environments. Furthermore, wet seasons are generally associated with lower ambient temperatures, which may reduce the environmental load of bacteria.

Unfortunately, when hand-washing stations were used by multiple households within the housing block they were a risk factor for a higher load of antibiotic-resistant E. coli. While this correlation seems counter-intuitive, it is consistent with these stations serving as fomites.
Moist surfaces around wash stations favor bacterial survival and proliferation, and the inconsistent availability of soap likely contributes to this outcome. This interpretation is supported by the association between lack of a hand-washing station and lower Amp resistance, and by behavioral practices for which handwashing after use of public toilets was associated with increased Amp-resistant $E$. coli in children and increased Tet-resistant E. coli in adults.

Like many communities in low-income countries [31-33], residents of Kibera have easy access to a limited diversity of antibiotics. For example, oral formulations of beta-lactams were the most used, with amoxicillin accounting for 50 and $56 \%$ of antibiotics used by households and children, respectively. Amoxicillin is a broadspectrum antibiotic that is used to treat acute respiratory and febrile illnesses, which are prevalent in this community [3] and for which residents report using antibiotics [11]. As might be expected, children consumed the most antibiotics within the household perhaps supporting the only positive correlation detected between antibiotic use and AMR (i.e., sulfamethoxazole and trimethoprim resistance) among children (Table 4). Sulfa drugs are used 
Table 4 Multivariable regression analysis for antimicrobial resistance load ( $\log _{10}$ CFU) at the adult level ( $\geq 18$ years)

\begin{tabular}{|c|c|c|c|c|c|}
\hline Predictor & $\begin{array}{l}\text { Ampicillin } \\
\beta[95 \% \mathrm{Cl}]\end{array}$ & $\begin{array}{l}\text { Streptomycin } \\
\beta[95 \% \mathrm{Cl}]\end{array}$ & $\begin{array}{l}\text { Sulfamethoxazole } \\
\beta[95 \% \mathrm{Cl}]\end{array}$ & $\begin{array}{l}\text { Tetracycline } \\
\beta[95 \% \mathrm{Cl}]\end{array}$ & $\begin{array}{l}\text { Trimethoprim } \\
\beta[95 \% \mathrm{Cl}]\end{array}$ \\
\hline \multicolumn{6}{|l|}{ Main water source ${ }^{a}$} \\
\hline Public-protected & $-0.47[-0.89,-0.05]$ & $-0.30[-0.75,0.16]$ & $-0.08[-0.39,0.22]$ & $-0.19[-0.65,0.27]$ & $-0.26[-0.55,0.03]$ \\
\hline Private-unprotected & $0.36[-1.88,2.60]$ & $0.49[-1.88,2.86]$ & $0.12[-1.52,1.76]$ & $0.83[-1.57,3.23]$ & $0.16[-1.46,1.78]$ \\
\hline Public-unprotected & $-0.27[-1.25,0.70]$ & $-0.09[-1.12,0.95]$ & $-0.29[-1.00,0.42]$ & $0.24[-0.80,1.29]$ & $-0.34[-1.04,0.35]$ \\
\hline Handwashing after urination & $0.07[-0.08,0.23]$ & $-0.03[-0.19,0.14]$ & $0.04[-0.08,0.15]$ & $0.18[0.01,0.34]$ & $0.04[-0.07,0.15]$ \\
\hline \multicolumn{6}{|l|}{ Handwashing facility location } \\
\hline Toilet within premises & $0.23[-0.18,0.64]$ & $0.12[-0.31,0.56]$ & $0.05[-0.24,0.35]$ & $0.23[-0.21,0.67]$ & $0.11[-0.17,0.40]$ \\
\hline Elsewhere on premises & $0.51[0.15,0.88]$ & $0.20[-0.19,0.59]$ & $0.30[0.04,0.57]$ & $0.42[0.02,0.81]$ & $0.29[0.03,0.54]$ \\
\hline No designated place & $-0.48[-0.85,-0.11]$ & $-0.24[-0.64,0.16]$ & $-0.07[-0.34,0.20]$ & $0.23[-0.17,0.63]$ & $-0.19[-0.45,0.06]$ \\
\hline Enrolled child eats soil & $0.41[0.02,0.79]$ & $0.24[-0.17,0.65]$ & $0.30[0.02,0.58]$ & $0.32[-0.09,0.74]$ & $0.23[-0.03,0.50]$ \\
\hline Rainfall (per mm) & $-3.26[-4.88,-1.65]$ & $-1.11[-2.82,0.59]$ & $-0.65[-1.84,0.54]$ & $0.47[-1.26,2.20]$ & $-1.79[-2.97,-0.61]$ \\
\hline School children (counts) & $0.03[-0.11,0.18]$ & $-0.02[-0.18,0.14]$ & $-0.13[-0.23,-0.03]$ & $-0.07[-0.23,0.09]$ & $-0.10[-0.20,-0.01]$ \\
\hline \multicolumn{6}{|l|}{ Mother's education level } \\
\hline Primary school & $-0.74[-1.69,0.21]$ & $-0.58[-1.62,0.46]$ & $0.07[-0.59,0.73]$ & $-0.21[-1.26,0.82]$ & $0.26[-0.33,0.86]$ \\
\hline High school & $-1.17[-2.15,-0.19]$ & $-0.76[-1.84,0.32]$ & $-0.02[-0.71,0.66]$ & $-0.44[-1.51,0.64]$ & $0.28[-0.33,0.89]$ \\
\hline College & $-1.78[-3.09,-0.47]$ & $-1.42[-2.85,0.02]$ & $-0.52[-1.44,0.39]$ & $-1.53[-2.97,-0.10]$ & $0.02[-0.80,0.84]$ \\
\hline Adult age (years) & $0.00[-0.03,0.03]$ & $0.02[-0.01,0.05]$ & $0.03[0.01,0.05]$ & $0.02[-0.01,0.05]$ & $0.03[0.01,0.05]$ \\
\hline
\end{tabular}

Only variables with $P<0.2$ in the univariable mixed-effects model were included in the multivariable model. Regression estimates for increasing or decreasing antimicrobial load (positive or negative $\beta$ coefficients, respectively) and $95 \%$ confidence intervals with $P<0.05$ are shown in bold. Only variables with significant values are shown. See Additional file 5 for complete table

a A protected source prevents contamination of water by the environment e.g. a source covered with a concrete slab or a completely covered tank

b Other than at a toilet facility or the household kitchen

Table 5 Multivariable regression analysis for antimicrobial resistance load ( $\log _{10} \mathrm{CFU}$ ) for children aged 0-5 years

\begin{tabular}{|c|c|c|c|c|c|}
\hline Predictors & $\begin{array}{l}\text { Ampicillin } \\
\beta[95 \% \mathrm{Cl}]\end{array}$ & $\begin{array}{l}\text { Streptomycin } \\
\beta[95 \% \mathrm{Cl}]\end{array}$ & $\begin{array}{l}\text { Sulfamethoxazole } \\
\beta[95 \% \mathrm{Cl}]\end{array}$ & $\begin{array}{l}\text { Tetracycline } \\
\beta[95 \% \mathrm{Cl}]\end{array}$ & $\begin{array}{l}\text { Trimethoprim } \\
\beta[95 \% \mathrm{Cl}]\end{array}$ \\
\hline \multicolumn{6}{|l|}{ Night toilet type } \\
\hline Ventilator improved pit & $0.03[-0.95,1.00]$ & $0.46[-0.73,1.64]$ & $0.25[-0.65,1.16]$ & $-0.59[-1.81,0.64]$ & $0.02[-0.81,0.86]$ \\
\hline Pit with concrete slab & $0.24[-0.38,0.86]$ & $0.41[-0.35,1.17]$ & $0.18[-0.39,0.76]$ & $-0.38[-1.17,0.41]$ & $0.06[-0.48,0.59]$ \\
\hline Traditional pit latrine $e^{a}$ & $0.00[-0.75,0.75]$ & $0.25[-0.66,1.16]$ & $0.14[-0.56,0.84]$ & $-1.39[-2.33,-0.45]$ & $0.20[-0.44,0.85]$ \\
\hline Bucket/plastic & $-0.08[-0.69,0.53]$ & $0.19[-0.55,0.93]$ & $-0.01[-0.57,0.56]$ & $-0.99[-1.77,-0.21]$ & $-0.17[-0.70,0.35]$ \\
\hline No facilities/open field & $-0.07[-1.05,0.91]$ & $-0.43[-1.63,0.76]$ & $-0.19[-1.09,0.72]$ & $-1.28[-2.56,0.00]$ & $-0.78[-1.63,0.06]$ \\
\hline Handwashing after urination & $0.20[0.03,0.38]$ & $0.06[-0.16,0.27]$ & $0.12[-0.04,0.28]$ & $0.08[-0.14,0.31]$ & $0.19[0.04,0.34]$ \\
\hline \multicolumn{6}{|l|}{ Handwashing facility location } \\
\hline Toilet within premises & $0.12[-0.23,0.47]$ & $0.19[-0.24,0.62]$ & $0.17[-0.16,0.50]$ & $0.28[-0.18,0.74]$ & $0.28[-0.03,0.58]$ \\
\hline Elsewhere on premises ${ }^{b}$ & $0.45[0.12,0.78]$ & $0.39[-0.01,0.79]$ & $0.35[0.05,0.66]$ & $0.26[-0.16,0.68]$ & $0.28[0.00,0.57]$ \\
\hline Child eats soil & $0.59[0.27,0.91]$ & $0.52[0.14,0.91]$ & $0.22[-0.08,0.52]$ & $0.80[0.40,1.21]$ & $0.25[-0.03,0.52]$ \\
\hline Rainfall (per mm) & $-2.02[-3.28,-0.76]$ & $-1.26[-2.80,0.27]$ & $-0.69[-1.85,0.47]$ & $1.74[0.07,3.40]$ & $-0.82[-1.91,0.27]$ \\
\hline Altitude (10 m increments) & $-0.01[-0.01,0.00]$ & $0.00[-0.01,0.01]$ & $-0.01[-0.01,0.00]$ & $-0.01[-0.01,0.00]$ & $-0.01[-0.01,0.00]$ \\
\hline Household used antibiotic & $0.39[-0.07,0.84]$ & $0.22[-0.34,0.77]$ & $0.46[0.04,0.88]$ & $0.10[-0.49,0.69]$ & $0.42[0.02,0.81]$ \\
\hline
\end{tabular}

Only variables with $P<0.2$ in the univariable mixed-effects model were included in the multivariable model. Regression estimates for increasing or decreasing antimicrobial load (positive or negative $\beta$ coefficients, respectively) and $95 \%$ confidence intervals with $P<0.05$ are shown in bold. Only variables with significant values are shown. See Additional file 6 for complete table

a Single pit covered by a wooden or earthen slab with a drop hole

b Other than at a toilet facility or the household kitchen 
to treat malaria and this practice has been correlated with the load of sulfamethoxazole-resistant $E$. coli in children [34]. While Kibera is not situated in a malaria-endemic area, travel to malaria-endemic areas is common among residents [35], and might contribute to this practice.

As a community, Kibera suffers from poor sanitation and a dense population, conditions that favor transmission of infectious diseases. It is unclear what proportion of antibiotic use in this setting is justified. Nevertheless, antibiotics likely provide a much-needed health benefit while inadvertently selecting for antibiotic-resistant bacteria. AMR transmission is a density-dependent process. Thus, when resistant bacteria in environments with poor sanitation are enriched from antibiotic use, ideal conditions for a steady production of antibiotic-resistant bacteria are achieved.

We acknowledge several limitations of our study. Firstly, self-reported data, inaccurate recall and biased responses could have increased variance in our results. Additionally, by sampling individuals who were available at home, our results may not be generalized to adult males and school-going children. Given that most enrolled adults were female household heads with extensive knowledge of household practices, and that household interactions facilitate "sharing" of germs, we surmise that our data were a reasonable representation of enrolled households. Secondly, we relied on colony morphology as the primary method to select presumptive E. coli isolates for analysis. Colony morphology, while not a reliable diagnostic for species identity, was 99.2\% consistent with $E$. coli based on a random subset of 248 isolates. We have successfully used this method for selecting $E$. coli for high-throughput assessment of antibiotic resistance in other studies [16, 36-38]. Thirdly, the "breakpoint" assay is not considered a diagnostic tool in a clinical microbiology lab but provides a low-cost means to analyze many isolates. We have assessed the validity of this method genotypically [36] and phenotypically [38].

\section{Conclusion}

Kibera experiences sanitation challenges that promote disease transmission and demand for antibiotics within a highly dense population. Under these conditions it is likely that selection of antibiotic-resistant bacteria within the gut, their disposal and enrichment within the environment, and recurrent transmission to humans occurs continuously. For communities that suffer such scenarios, the fight against antibiotic-resistant bacteria will require significant reduction in the burden of infectious disease coupled with markedly improved sanitation at the household and community levels.

\section{Supplementary Information}

The online version contains supplementary material available at https://doi. org/10.1186/s13756-021-00886-y.

Additional file 1. Water, Sanitation and Hygiene Questionnaire.

Additional file 2. Antibiotic use Questionnaire.

Additional file 3. Nine of the most abundant (found in > of all E. coli isolates) resistance phenotypes out of 148 unique combinations. The number of isolates and their proportional representation (\%) of the total are shown. Profile marked with an asterisk $\left({ }^{*}\right)$ denotes the penta-resistant phenotype.

Additional file 4. Multivariable regression analysis for antimicrobial resistance load ( $\log _{10}$ CFU) at the household level. Only variables with $P<0.2$ in the univariable mixed-effects model were included in the multivariable model. Regression estimates $(\beta)$ and 95\% confidence intervals with $P<$ 0.05 are shown in bold. $P=0.00$ indicates $P<0.01$.

Additional file 5. Multivariable regression analysis for antimicrobial resistance load $\left(\log _{10}\right.$ CFU) at the adult level ( $\geq 18$ years). Only variables with $P<0.2$ in the univariable mixed-effects model were included in the multivariable model. Regression estimates $(\beta)$ and 95\% confidence intervals with $P<0.05$ are shown in bold. $P=0.00$ indicates $P<0.01$.

Additional file 6. Multivariable regression analysis for antimicrobial resistance load ( $\log _{10}$ CFU) for children aged $0-5$ years. Only variables with $P<$ 0.2 in the univariable mixed-effects model were included in the multivariable model. Regression estimates $(\beta)$ and $95 \%$ confidence intervals with $P$ $<0.05$ are shown in bold. $P=0.00$ indicates $P<0.01$.

\section{Abbreviations}

AMR: Antimicrobial resistance; CDC: Centers for Disease Control and Prevention; CFU: Colony-forming units; KEMRI: Kenya Medical Research Institute; PBIDS: Population-based infectious disease surveillance; PBS: Phosphatebuffered saline.

\section{Acknowledgements}

This study was made possible by the receptiveness of the Kibera community residents, to whom we are truly grateful. We acknowledge with deep gratitude the efforts by the field and laboratory data collection teams and their supervisors. Special thanks to various faculty at the Paul G. Allen School for Global Animal Health (SGAH) at Washington State University, (USA) who contributed to the design of this study and continuously mentored SO during the study. We thank our collaborators at the Kenya Medical Research Institute (KEMRI) and the Centers for Disease Control and Prevention-Kenya for contributing resources towards this study, and the Paul G. Allen SGAH for the generous funding that enabled the completion of this study. We also thank the KEMRI Director for approving the publication of this work. The findings and conclusions in this report are those of the authors and do not necessarily represent the official position of the Centers for Disease Control and Prevention.

\section{Authors' contributions}

SO, STM, MKN, TFM, and DRC conceptualized and designed the study. SO, STM, $\mathrm{GB}, \mathrm{AO}, \mathrm{JV}, \mathrm{BJ}$, and SK planned and completed data collection. SO conducted the laboratory analysis, and with ETL, SL, STM, GHP, and DRC did the statistical analyses. SO, ETL, SL, GHP, and DRC wrote the first draft of the manuscript, which was critically reviewed and revised by all other authors. GB, AO, JRV, BJ, MKN, SK, TFM, GHP, and DRC contributed human, technical and financial resources towards the execution of the study. All authors read and approved the final manuscript.

\section{Funding}

Funded by the Paul G. Allen School for Global Animal Health, Washington State University, US. The funder had no role in the design of the study, in its data collection and analysis processes, or the decision to prepare or publish the manuscript. 


\section{Availability of data and materials}

The datasets used and/or analyzed during the current study are available from the corresponding author on reasonable request.

\section{Ethics approval and consent to participate}

This study was approved by the KEMRI Scientific and Ethics Review Committee (\#2998), the CDC (\#6761; reliance agreement between KEMRI and CDC) and the Washington State University Institutional Review Board (\#14413). Oral and written informed consent were obtained from adult respondents and from a guardian of each enrolled child prior to enrollment. No incentives were provided to respondents.

\section{Consent for publication}

Not applicable.

\section{Competing interests}

Not applicable.

\section{Author details}

${ }^{1}$ Paul G. Allen School for Global Animal Health, Washington State University, Pullman, WA, USA. ${ }^{2}$ Washington State University Global Health-Kenya, Nairobi, Kenya. ${ }^{3}$ Center for Global Health Research, Kenya Medical Research Institute, Kisumu, Kenya. ${ }^{4}$ Centers for Disease Control and Prevention, Nairobi, Kenya. ${ }^{5}$ Center for Microbiology Research, Kenya Medical Research Institute, Nairobi, Kenya. ${ }^{6}$ Nelson Mandela African Institution for Science and Technology, Arusha, Tanzania.

Received: 25 August 2020 Accepted: 5 January 2021

Published online: 22 January 2021

\section{References}

1. World Health Organization, WHO. Antimicrobial resistance: global report on surveillance. 2014. https://doi.org/10.1007/s13312-014-0374-3.

2. Bygbjerg IC. Double burden of noncommunicable and infectious diseases in developing countries. Science. 2012;337:1499-501. https://doi. org/10.1126/science.1223466.

3. Feikin DR, Olack B, Bigogo GM, Audi A, Cosmas L, Aura B, et al. The burden of common infectious disease syndromes at the clinic and household level from population-based surveillance in rural and urban Kenya. PLoS ONE. 2011;6:e16085. https://doi.org/10.1371/journal.pone.0016085.

4. Riley LW, Ko Al, Unger A, Reis MG. Slum health: diseases of neglected populations. BMC Int Health Hum Rights. 2007;7:2. https://doi. org/10.1186/1472-698X-7-2.

5. United Nations Human Settlements Programme (UN-Habitat). World Cities Report 2016: Urbanization and Development-Emerging Futures. Nairobi; 2016. http://wcr.unhabitat.org/wp-content/uploads/2017/02/ WCR-2016-Full-Report.pdf. Accessed 13 Jul 2017.

6. Planta MB. The Role of Poverty in Antimicrobial Resistance. J Am Board Fam Med. 2007;20:533-9. https://doi.org/10.3122/jabfm.2007.06.070019.

7. Okeke IN. Poverty and root causes of resistance in developing countries. In: Antimicrobial resistance in developing countries. New York, NY: Springer; 2010. p. 27-35. https://doi.org/10.1007/978-0-387-89370-9_3.

8. Ocan M, Obuku EA, Bwanga F, Akena D, Richard S, Ogwal-Okeng J, et al. Household antimicrobial self-medication: a systematic review and meta-analysis of the burden, risk factors and outcomes in developing countries. BMC Public Health. 2015;15:742. https://doi.org/10.1186/s1288 9-015-2109-3.

9. Collignon P, Beggs JJ, Walsh TR, Gandra S, Laxminarayan R. Anthropological and socioeconomic factors contributing to global antimicrobial resistance: a univariate and multivariable analysis. Lancet Planet Heal. 2018;2:e398-405. https://doi.org/10.1016/S2542-5196(18)30186-4.

10. Njuguna HN, Cosmas L, Williamson J, Nyachieo D, Olack B, Ochieng JB, et al. Use of population-based surveillance to define the high incidence of shigellosis in an urban slum in Nairobi. Kenya PLoS One. 2013;8:e58437. https://doi.org/10.1371/journal.pone.0058437.

11. Omulo S, Thumbi SM, Lockwood S, Verani JR, Bigogo G, Masyongo $\mathrm{G}$, et al. Evidence of superficial knowledge regarding antibiotics and their use: results of two cross-sectional surveys in an urban informal settlement in Kenya. PLoS ONE. 2017;12:e0185827. https://doi. org/10.1371/journal.pone.0185827.

12. Kenya National Bureau of Statistics. 2019 Kenya population and housing census volume II: distribution of population by administrative units. 2019 . http://www.knbs.or.ke.

13. National Aeronautical and Space Administration (NASA). TRMM data downloads/precipitation measurement missions. https://pmm.nasa.gov/ data-access/downloads/trmm. Accessed 4 Aug 2016.

14. Worrell CM, Wiegand RE, Davis SM, Odero KO, Blackstock A, Cuéllar VM, et al. A cross-sectional study of water, sanitation, and hygiene-related risk factors for soil-transmitted helminth infection in urban school- and preschool-aged children in Kibera, Nairobi. PLoS ONE. 2016;11:e0150744. https://doi.org/10.1371/journal.pone.0150744.

15. World Health Organization (WHO), United Nations Children's Fund (UNICEF). Core questions on drinking water and sanitation for household surveys. Geneva; 2006.

16. Omulo S, Lofgren ET, Mugoh M, Alando M, Obiya J, Kipyegon K, et al. The impact of fecal sample processing on prevalence estimates for antibioticresistant Escherichia coli. J Microbiol Methods. 2017;136:71-7. https://doi. org/10.1016/j.mimet.2017.03.006.

17. R Core Team. R: A language and environment for statistical computing. $R$ foundation for statistical computing. Vienna, Austria; 2016. http://www.rproject.org/.

18. Breiman RF, Cosmas L, Njenga MK, Williamson J, Mott JA, Katz MA, et al. Severe acute respiratory infection in children in a densely populated urban slum in Kenya, 2007-2011. BMC Infect Dis. 2015;15:1-11. https:// doi.org/10.1186/s12879-015-0827-x.

19. World Health Organization. WHO multi-country survey reveals widespread public misunderstanding about antibiotic resistance. World Health Organisation. 2015; November:1-7. http://www.who.int/en/newsroom/detail/16-11-2015-who-multi-country-survey-reveals-widespread -public-misunderstanding-about-antibiotic-resistance\#. Accessed 27 Oct 2016.

20. Zhong W, Maradit-Kremers H, St Sauver JL, Yawn BP, Ebbert JO, Roger VL, et al. Age and sex patterns of drug prescribing in a defined American population. Mayo Clin Proc. 2013;88:697-707. https://doi.org/10.1016/j. mayocp.2013.04.021.

21. Jasper C, LeT-T, Bartram J. Water and sanitation in schools: a systematic review of the health and educational outcomes. Int J Environ Res Public Health. 2012;9:2772-87. https://doi.org/10.3390/ijerph9082772.

22. Kathure Mbae C, Nokes DJ, Mulinge E, Nyambura J, Waruru A, Kariuki S. Intestinal parasitic infections in children presenting with diarrhoea in outpatient and inpatient settings in an informal settlement of Nairobi, Kenya. BMC Infect Dis. 2013. https://doi.org/10.1186/1471-2334-13-243.

23. Oloruntoba EO, Folarin TB, Ayede Al. Hygiene and sanitation risk factors of diarrhoeal disease among under-five children in Ibadan, Nigeria. Afr Health Sci. 2014;14:1001-11.

24. Taylor DL, Kahawita TM, Cairncross S, Ensink JHJ. The impact of water, sanitation and hygiene interventions to control cholera: a systematic review. PLOS ONE. 2015;10:1-19.

25. Olack B, Burke H, Cosmas L, Bamrah S, Dooling K, Feikin DR, et al. Nutritional status of under-five children living in an informal urban settlement in Nairobi. Kenya J Health Popul Nutr. 2011;29:357-63.

26. Corburn J, Hildebrand C. Slum sanitation and the social determinants of women's health in Nairobi, Kenya. J Environ Public Health. 2015. https:// doi.org/10.1155/2015/209505.

27. O'Neill J. Tackling drug-resistant infections globally: final report and recommendations. London. 2016. https://doi.org/10.1016/j.jpha.2015.11.005.

28. Bartoloni A, Bartalesi F, Mantella A, Dell'Amico E, Roselli M, Strohmeyer M, et al. High prevalence of acquired antimicrobial resistance unrelated to heavy antimicrobial consumption. J Infect Dis. 2004;189:1291-4. https:// doi.org/10.1086/382191.

29. African Population and Health Research Center (APHRC). Population and health dynamics in Nairobi's informal settlements: Report of the Nairobi Cross-Sectional Slums Survey (NCSS) 2012. Nairobi; 2014.

30. Bauza V, Ocharo RM, Nguyen TH, Guest JS. Soil ingestion is associated with child diarrhea in an urban slum of Nairobi, Kenya. Am J Trop Med Hyg. 2017;96:569-75. https://doi.org/10.4269/ajtmh.16-0543.

31. Borg MA, Zarb P, Scicluna EA, Rasslan O, Gur D, Ben Redjeb S, et al. Antibiotic consumption as a driver for resistance in Staphylococcus aureus 
and Escherichia coli within a developing region. Am J Infect Control. 2010;38:212-6. https://doi.org/10.1016/j.ajic.2009.07.010.

32. Auta A, Banwat SB, David S, Dangiwa DA, Ogbole E, Tor-Anyiin AJ. Antibiotic use in some Nigerian communities: knowledge and attitudes of consumers. Trop J Pharm Res. 2013;12:1087-92.

33. Kehinde $\mathrm{OO}$, Ogunnowo $\mathrm{BE}$. The pattern of antibiotic use in an urban slum in Lagos State, Nigeria Olanike. West African J Pharm. 2013;24:49-57.

34. Kalter HD, Gilman RH, Moulton LH, Cullotta AR, Cabrera L, Velapatiño B. Risk factors for antibiotic-resistant Escherichia coli carriage in young children in Peru: community-based cross-sectional prevalence study. Am J Trop Med Hyg. 2010;82:879-88. https://doi.org/10.4269/ajtmh .2010.09-0143.

35. Njuguna HN, Montgomery JM, Cosmas L, Wamola N, Oundo JO, Desai M, et al. Malaria parasitemia among febrile patients seeking clinical care at an outpatient health facility in an urban informal settlement area in Nairobi, Kenya. Am J Trop Med Hyg. 2016;94:122-7. https://doi.org/10.4269/ ajtmh.15-0293.
36. Subbiah M, Caudell MA, Mair C, Davis MA, Matthews L, Quinlan RJ, et al. Antimicrobial resistant enteric bacteria are widely distributed amongst people, animals and the environment in Tanzania. Nat Commun. 2020;11.

37. Caudell MA, Quinlan MB, Subbiah M, Call DR, Roulette CJ, Roulette JW, et al. Antimicrobial use and veterinary care among agro-pastoralists in Northern Tanzania. PLoS ONE. 2017;12:e0170328. https://doi.org/10.1371/ journal.pone.0170328.

38. Ramay BM, Caudell MA, Cordón-Rosales C, Archila LD, Palmer GH, Jarquin $C$, et al. Antibiotic use and hygiene interact to influence the distribution of antimicrobial-resistant bacteria in low-income communities in Guatemala. Sci Rep. 2020. https://doi.org/10.1038/s41598-020-70741-4.

\section{Publisher's Note}

Springer Nature remains neutral with regard to jurisdictional claims in published maps and institutional affiliations.
Ready to submit your research? Choose BMC and benefit from:

- fast, convenient online submission

- thorough peer review by experienced researchers in your field

- rapid publication on acceptance

- support for research data, including large and complex data types

- gold Open Access which fosters wider collaboration and increased citations

- maximum visibility for your research: over 100M website views per year

At BMC, research is always in progress.

Learn more biomedcentral.com/submissions 